\title{
Same Admission Hybrid Treatment of Primary Upper Extremity Deep Venous Thrombosis with Thrombolysis, Transaxillary Thoracic Outlet Decompression, and Immediate Endovascular Evaluation
}

Citation for published version (APA):

Pesser, N., Bode, A., Goeteyn, J., Hendriks, J., van Nuenen, B. F. L., van Sambeek, M. R. H. M., \& Teijink, J. A. W. (2021). Same Admission Hybrid Treatment of Primary Upper Extremity Deep Venous Thrombosis with Thrombolysis, Transaxillary Thoracic Outlet Decompression, and Immediate Endovascular Evaluation. Annals of Vascular Surgery, 71, 249-256.

https://doi.org/10.1016/j.avsg.2020.07.052

Document status and date:

Published: 01/02/2021

DOI:

10.1016/j.avsg.2020.07.052

Document Version:

Publisher's PDF, also known as Version of record

\section{Document license:}

Taverne

Please check the document version of this publication:

- A submitted manuscript is the version of the article upon submission and before peer-review. There can be important differences between the submitted version and the official published version of record. People interested in the research are advised to contact the author for the final version of the publication, or visit the DOI to the publisher's website.

- The final author version and the galley proof are versions of the publication after peer review.

- The final published version features the final layout of the paper including the volume, issue and page numbers.

Link to publication

\footnotetext{
General rights rights.

- You may freely distribute the URL identifying the publication in the public portal. please follow below link for the End User Agreement:

www.umlib.nl/taverne-license

Take down policy

If you believe that this document breaches copyright please contact us at:

repository@maastrichtuniversity.nl

providing details and we will investigate your claim.
}

Copyright and moral rights for the publications made accessible in the public portal are retained by the authors and/or other copyright owners and it is a condition of accessing publications that users recognise and abide by the legal requirements associated with these

- Users may download and print one copy of any publication from the public portal for the purpose of private study or research.

- You may not further distribute the material or use it for any profit-making activity or commercial gain

If the publication is distributed under the terms of Article $25 \mathrm{fa}$ of the Dutch Copyright Act, indicated by the "Taverne" license above,

Download date: 26 Apr. 2023 


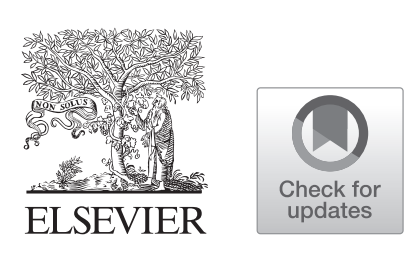

\title{
Same Admission Hybrid Treatment of Primary Upper Extremity Deep Venous Thrombosis with Thrombolysis, Transaxillary Thoracic Outlet Decompression, and Immediate Endovascular Evaluation
}

\author{
Niels Pesser, ${ }^{1}$ Aron Bode, ${ }^{1}$ Jens Goeteyn, ${ }^{1}$ Joris Hendriks, ${ }^{2}$ Bart F.L. van Nuenen, ${ }^{3}$ \\ Marc R.H.M. van Sambeek, ${ }^{1,4}$ and Joep A.W. Teijink, ${ }^{1,5}$ Eindhoven, The Netherlands
}

\begin{abstract}
Background: Multiple algorithms exist for treating acute primary upper extremity deep venous thrombosis (pUEDVT) caused by venous thoracic outlet syndrome (VTOS). In this case series, we present the results of our dedicated same admission treatment algorithm.

Methods: All patients between January 2015 and December 2019 with an established acute upper extremity deep venous thrombosis (symptoms $<14$ days) caused by VTOS were treated according to an algorithm consisting of same admission thrombolysis, transaxillary thoracic outlet decompression (TA-TOD) with extensive venolysis, and venography. If a residual stenosis of the subclavian vein was identified on venography, including by means of low-pressure diagnostic balloon inflation, correction by percutaneous transluminal angioplasty (PTA) was performed. The thoracic outlet syndrome disability scale, the Dutch language version of the disabilities of the arm, shoulder, and hand, and the VEINES-quality of life (VEINES-QOL/VEINESsymptoms) questionnaires were collected during follow-up.

Results: In total, 10 patients were treated for acute pUEDVT. After successful thrombolysis $(100 \%)$ and TA-TOD, immediate venography showed residual stenosis of the subclavian vein in 8 of 10 patients $(80 \%)$. Low-pressure dilatation of a balloon suited to the geometry of the axillosubclavian vein showed significant tapering in all cases (10/10) after which a formal venous PTA was performed. No stents were used. Mean time to discharge was 6.4 days. All patients were free of symptoms at a mean follow-up period of 34.4 months. Eight of the 10 patients completed follow-up questionnaires and reported a mean thoracic outlet syndrome disability scale of 0.6 , mean disabilities of the arm, shoulder, and hand score of 4.2, and a median VEINES-Symptoms of 55.23 (IQR, 12.13), and VEINES-QOL of 55.29 (IQR, 15.42).

Conclusions: A same admission treatment algorithm for acute pUEDVT in patients with VTOS including thrombolysis, TA-TOD with extensive venolysis, and immediate venography with PTA is effective with promising intermediate results.
\end{abstract}

Conflict of interest: None to report.

Funding: This research did not receive any specific grant from funding agencies in the public, commercial, or not-for-profit sectors.

${ }^{I}$ Department of Vascular Surgery, Catharina Hospital, Eindhoven, The Netherlands.

${ }^{2}$ Department of Radiology, Catharina Hospital, Eindhoven, The Netherlands.

${ }^{3}$ Department of Neurology, Catharina Hospital, Eindhoven, The Netherlands.

${ }^{4}$ Department of Biomedical Technology, University of Technology Eindhoven, Eindhoven, The Netherlands.
${ }^{5}$ CAPHRI School for Public Health and Primary Care, Faculty of Health, Medicine and Life Sciences, Maastricht University, Maastricht, The Netherlands.

Correspondence to: Joep A.W. Teijink, MD PhD, Vascular Surgeon, Department of Vascular Surgery Catharina Hospital, Michelangelolaan 2, 5623 EJ Eindhoven, P.O. Box 1350, 5602 ZA Eindhoven, The Netherlands; E-mail: joep.teijink@catharinaziekenhuis.nl

Ann Vasc Surg 2021; 71: 249-256

https://doi.org/10.1016/j.avsg.2020.07.052

(C) 2020 Elsevier Inc. All rights reserved.

Manuscript received: May 1, 2020; manuscript accepted: July 27, 2020; published online: 12 August 2020 


\section{INTRODUCTION}

Venous thoracic outlet syndrome (VTOS) is caused by repetitive compressive injury to the axillosubclavian vein (ASV) that results in a cycle of inflammation and fibrosis of the vein wall and its adjacent structures. ${ }^{1}$ This compression is often the consequence of an abnormal inserted costoclavicular ligament and/or hypertrophy of the anterior scalene muscle and/or subclavius muscle that narrow(s) the thoracic inlet. Ultimately, acute primary upper extremity deep venous thrombosis (pUEDVT) may result and this characteristically affects young, healthy, and active people with an incidence of approximately $1-2$ per 100.000 people per year. ${ }^{1-3}$

The management of acute pUEDVT is controversial. Most guidelines suggest the use of anticoagulant therapy as primary treatment. ${ }^{4,5}$ However, some experts suggest that full recovery after acute pUEDVT and prevention of chronic VTOS with post-thrombotic syndrome (PTS) complaints is best established by a more aggressive approach consisting of anticoagulant therapy in combination with thrombolysis and surgical thoracic outlet decompression (TOD), preferably within the first 14 days after the onset of symptoms. ${ }^{1,6}$ Although some favor this aggressive treatment, different opinions regarding surgical approach, timing of TOD, and management after TOD with percutaneous transluminal angioplasty (PTA), stents, and/or venous bypass procedures remain. $^{6-8}$

Correcting the anatomic substrate by TOD is, besides a fast start of initial treatment, thought to be helpful in preventing PTS and recurrent venous thromboembolism in patients with acute pUEDVT. ${ }^{1,9}$ However, residual lesions in the subclavian vein after TOD are a common finding. ${ }^{10-13}$ The residual stenosis can be treated by patch venoplasty, venous bypass grafting during paraclavicular TOD surgery, or PTA with or without stent placement. Thrombolysis followed by TOD, with immediate PTA addresses both the anatomic substrate and the residual stenosis in patients with acute pUEDVT. In this study, we present the results of a same admission algorithm in a case series of 10 patients.

\section{METHODS}

\section{Study Design and Participants}

We evaluated all patients that were referred to the Department of Vascular Surgery of the Catharina Hospital Eindhoven, The Netherlands, between January 2015 and December 2019 for diagnosis and treatment of upper extremity deep venous thrombosis (UEDVT) caused by VTOS. Patients were identified in a prospectively collected database. This study was approved by the local ethics committee and informed consent was obtained from all individuals after treatment.

According to the Reporting Standards for TOS, patients were classified into acute $(<14$ days $)$, subacute (14 days-3 months), or chronic ( $\geq 3$ months) VTOS. ${ }^{14}$ Patients were included in this study if they presented with an acute pUEDVT $(<14$ days) in the ASV with relation to compression on venography and no other explanation for UEDVT (e.g., malignancy, catheter). Patients presenting with chronic or subacute symptoms, or secondary causes of UEDVT (e.g., catheter or malignancy based) were excluded from these series.

Data collection included medical history, demographics, clotting disorders, dominant hand, side of symptoms, time between event and presentation, provoking factors, and findings of clinical examination. All patients were clinically evaluated by a dedicated TOS surgeon (J.A.W.T. or M.R.H.M.S.). During history and physical examination there was explicit attention for the presence of coexisting neurogenic TOS. Chest X-ray of the superior thoracic aperture was made to reveal possible bony anatomic abnormalities (e.g., cervical ribs, abnormal first ribs, or an elongated transverse process of C7). Finally, both duplex ultrasonography and digital subtraction contrast venography of the upper extremity were performed to identify the venous occlusion and to assess its extent.

After presentation and identification of axillosubclavian thrombus, thrombolysis was started as soon as possible. First, the thrombus was passed with a guidewire after which a thrombolysis catheter was put in place for delivery of the thrombolytic agent. Alteplase (Boehringer Ingelheim, Ingelheim, Germany) therapy was used in all patients by first giving a lacing bolus of $5 \mathrm{mg}$. Thereafter, infusion with Alteplase was continued with $1 \mathrm{mg} / \mathrm{hr}$ for $12 \mathrm{hr}$ followed by $0.5 \mathrm{mg} / \mathrm{hr}$ after $12 \mathrm{hr}$ until there was no progression of thrombolysis on sequential examinations, or until complete thrombus dissolution was achieved. If high-grade stenosis was visible on sequential venography studies despite thrombolysis, a $6 \mathrm{~mm}$ PTA was performed preoperatively to enhance post-TOD catheterization. After stopping thrombolysis, lowmolecular-weight heparin (LMWH; Nadroparin, Fraxodi; GlaxoSmithKline, Brentford, UK) prophylaxis was continued until the evening before TOD surgery. However, in patients treated in 2015 and $2016(n=4)$ LMWH prophylaxis was continued periprocedurally. 


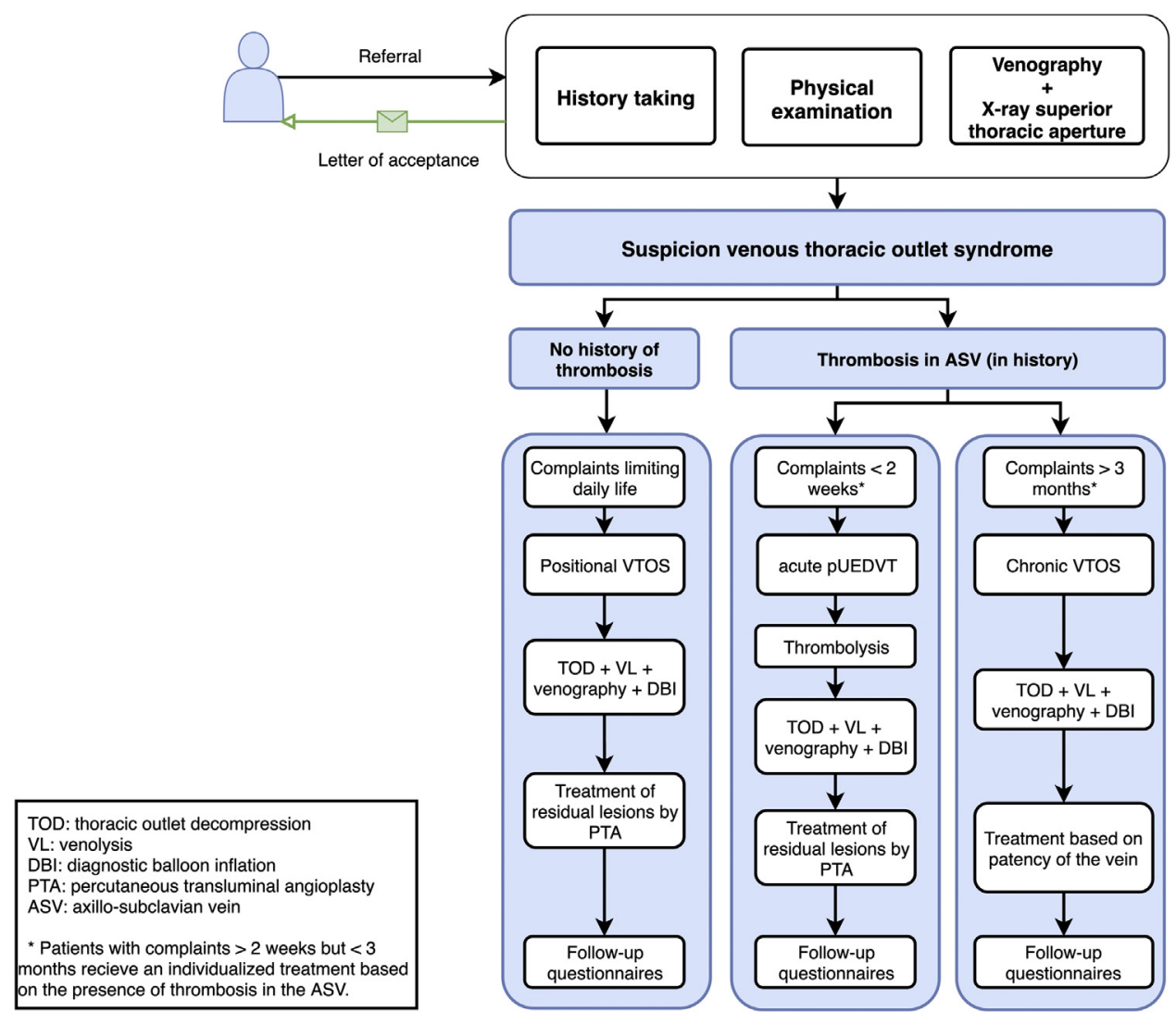

Fig. 1. Care pathway for VTOS including the pUEDVT treatment algorithm.

After successful thrombolysis, same admission transaxillary thoracic outlet decompression (TATOD) was performed in a hybrid operating room. The procedure was performed under general anesthesia with the addition of interfascial plane blockade to reduce postoperative pain as described previously. ${ }^{15}$ During this procedure, a complete first rib resection from the costochondral junction to the articulation with the vertebral body's transverse process (the neck of the first rib remains), a partial anterior and medial scalenectomy (15-20 mm lower part), medial 3-4 cm removal of the subclavius muscle, and a thorough circumferential venolysis of the ASV was performed. After closure of the axillary wound, a venography through the basilic vein or brachial vein was performed to assess the patency of the vein. In addition, an $8 \times 40 \mathrm{~mm}$ balloon (Passeo-35; Biotronik, Berlin, Germany) was advanced to the level of the thoracic inlet/outlet and slowly inflated to $2 \mathrm{~atm}$ under fluoroscopic guidance to visualize the presence of residual stenosis. If a stenosis was identified on this diagnostic balloon inflation, as evidenced by tapering of the balloon, a formal PTA (with nominal to burst pressures of the balloon) was performed with a balloon suitable to the geometry of the vessel. Postoperative therapeutic anticoagulation with rivaroxaban 20 mg once daily (Xarelto; Bayer, Leverkusen, Germany) was initiated directly after TOD surgery and continued for 6 weeks in all patients. A summary of the complete VTOS care pathway including the pUEDVT treatment algorithm is displayed in Figure 1.

All patients were evaluated 6 weeks after surgery and then yearly. No additional duplex ultrasonography or venography was performed in patients without sequelae or complaints during physical examination. However, a low threshold venography was performed if a patient reported even minimal sequelae or when abnormalities during physical examination were observed. Sequelae were defined as swelling, edema, pain, discoloration, and heaviness in rest or during strenuous activity. If venography in these patients showed a reduced diameter of the vein, a re-PTA was performed. Patients were seen 6 weeks after intervention and thereafter in case of sequelae. Additional follow-up data were obtained by questionnaires consisting of the thoracic outlet 
Table I. Baseline characteristics

\begin{tabular}{ll}
\hline Patient characteristics & $\begin{array}{l}n=10 \\
(100 \%)\end{array}$ \\
\hline Gender, male (\%) & $6(60)$ \\
Age, range & $34(22-59)$ \\
Side with symptoms, $n(\%)$ & \\
$\quad$ Right side & $3(30)$ \\
Left side & $7(70)$ \\
More episodes of UEDVT & $1(10 \%)$ \\
Symptoms & \\
Swelling & $10(100)$ \\
Discoloration & $5(50)$ \\
Collateralization & $4(40)$ \\
Pain during exercise & $2(20)$ \\
Effort-induced complaints & $3(30)$ \\
Clotting disorders & $0(0)$ \\
Prior trauma to chest, & $1(10)$ \\
$\quad$ clavicle, shoulder, ribs & \\
Signs of neurogenic TOS & $0(0)$ \\
Cervical rib on X-ray imaging & $0(0)$ \\
Elongated C7 transverse & $1(10)$ \\
process on X-ray & \\
Imaging & \\
Deviations on duplex &
\end{tabular}

syndrome (TOS) disability scale, the Dutch language version of the disabilities of the arm, shoulder, and hand (DASH) score, return to work, and quality of life by VEINES-symptoms (VEINES-SYM) and VEINES-quality of life (VEINES-QOL). The mean DASH score in a general population with comparable age is 5-10 points. $^{16}$ VEINES-SYM and VEINES-QOL scores for patients with PTS are reported around 34 points compared with 53 points for patients without PTS symptoms. ${ }^{17}$

\section{Statistical Analysis}

The statistical analysis was performed using Statistical Product and Service Solutions (SPSS) 25 (IBM Corporate, Armonk, New York, USA). Data are presented as the means with ranges and medians with interquartile ranges for VEINES scores. The VEINES-QOL/VEINES-SYM was calculated using the intrinsic method, allowing comparison between other cohorts. $^{18}$

\section{RESULTS}

In total, 52 patients were surgically treated for VTOS during the study period of which 10 of 52 patients had acute symptoms related to pUEDVT and were

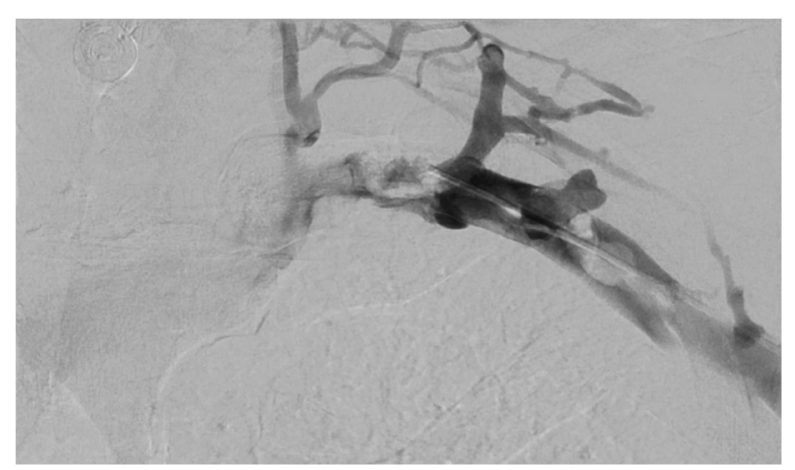

Fig. 2. Occlusion of the ASV in pUEDVT "patient $x^{\prime \prime}$ before thrombolysis.

eligible for inclusion based on duration of complaints $<14$ days. Mean age was 34 years (range, 22-59), and 6 patients $(60 \%)$ were men. The mean time between initial complaints and presentation in our outpatient clinic was 7.2 days $(1-12)$. Clotting disorders were not found in our cohort. One patient had 2 previous episodes of acute pUEDVT on the same side. Symptoms of neurologic or arterial TOS were not found in this series. All baseline characteristics following the reporting standards for TOS are summarized in Table $\mathrm{I}^{14}$

In all patients (10/10), a diagnostic venography was performed showing a thrombus in the ASV in all cases (Fig. 2). Collateralization as evidenced by visible vessels on the thoracic wall was seen in 8 of 10 patients. Subsequently, thrombolysis was initiated in all individuals within $24 \mathrm{hr}$ after presentation. Thrombolysis was continued with a mean duration of $39 \mathrm{hr}$ (range, 19-66). Progression of thrombus dissolution was seen in all patients $(100 \%)$ but a remaining high-grade stenosis was seen in 2 patients, requiring preoperative PTA with a $6 \times 40 \mathrm{~mm}$ balloon (Passeo-35; Biotronik) to enhance post-TOD catheterization.

After thrombolysis, TA-TOD with circumferential venolysis was performed in all (10) patients. No cervical rib or fibrous band was assessed in this series. During the intraoperative venography a residual stenosis of the ASV was visualized in 8 of 10 patients (Fig. 3). Moreover, tapering during the low-pressure diagnostic balloon inflation revealed persisting stenosis in all (10/10) patients (Fig. 4). Therefore, a formal angioplasty was executed in every case $(2$ times an $8 \mathrm{~mm}$ balloon, 6 times a $10 \mathrm{~mm}$ balloon, and 2 times a $12 \mathrm{~mm}$ balloon) (Powerflex; Cordis, Miami, FL). In all patients this approach resulted in a patent ASV without residual stenosis at the end of the procedure (Fig. 5). Complete disappearance of collaterals after PTA was seen in 6 patients, and partial in the remaining 4 patients. The overall 


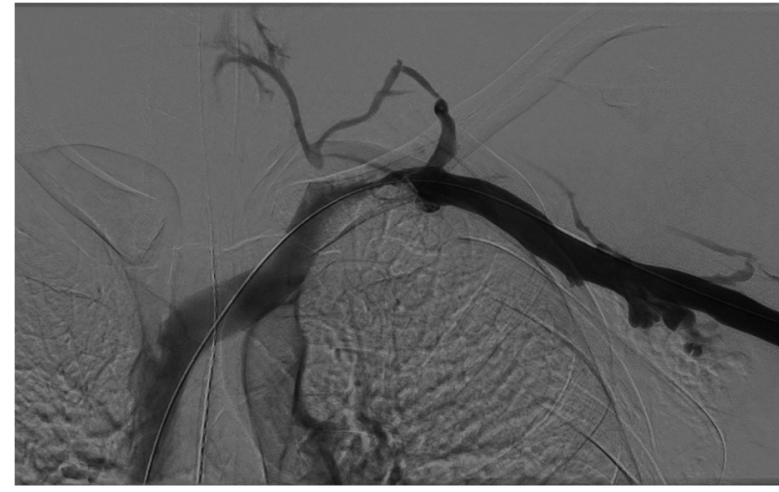

Fig. 3. Situation after thrombolysis and TOD with venolysis.

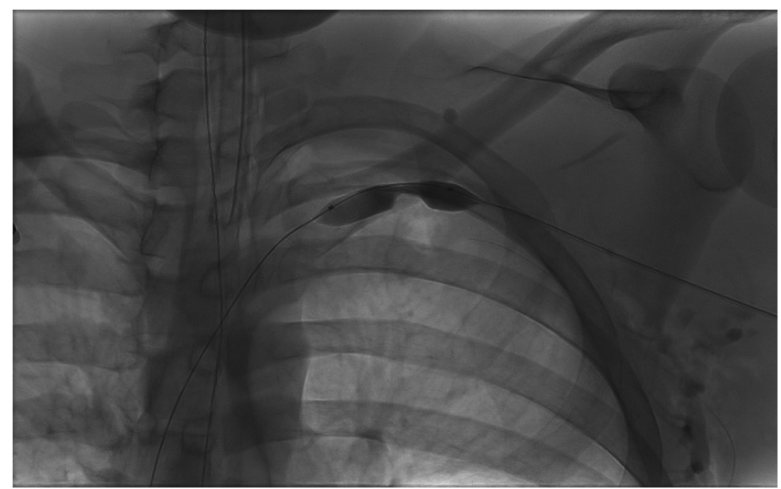

Fig. 4. Example of tapering during test-PTA after thoracic outlet decompression surgery.

length of stay was 6.4 days (range, 2-15 days). Mean time from presentation to TOD surgery was $89 \mathrm{hr}$ (range, 45-142). Postoperative length of stay was 3.2 days (range, $1-12$ days). Surgical data are summarized in Table II.

Postoperative complications included 2 patients with hematoma formation requiring reexploration. In 1 patient, a small active bleeding vessel was found, which was controlled during reintervention. No active bleeding was found in the second patient and removal of hematoma was performed. Other complications such as pneumothorax, wound infection, phrenic or long thoracic nerve palsies, or brachial plexus injuries were not seen.

At the time of writing, all patients were asymptomatic without symptoms of PTS with a mean follow-up of 34.4 months (range, 6-58). However, recurrent symptoms were reported during followup in 3 of 10 patients and consisted of swelling (3/ 3 patients), pain (2/3 patients), and discoloration (1/3 patients). Venography showed a decrease in diameter without rethrombosis of the ASV in all these patients and a second PTA was performed.

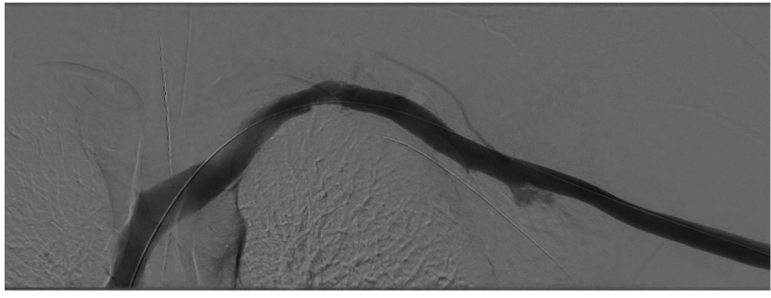

Fig. 5. Situation after same admission thrombolysis, TOD with venolysis, and PTA.

Table II. Surgical data

\begin{tabular}{lc}
\hline Surgical data & $\begin{array}{l}n=10 \\
(100 \%)\end{array}$ \\
\hline $\begin{array}{l}\text { Mean delay to presentation } \\
\text { in our clinic (days) }\end{array}$ & $7.2(1-12)$ \\
Successful wire passage & $10(100)$ \\
Intraoperative PTA performed & $10(100)$ \\
Re-PTA after initial TOD + PTA & $3(30)$ \\
Mean time to Re-PTA (days) & $32.3(11-49)$ \\
Complications & $0(0)$ \\
$\quad$ Brachial plexus injury & $0(0)$ \\
Superficial infection & $2(20)$ \\
Postoperative bleeding & $0(0)$ \\
Pneumothorax & $0(0)$ \\
Scapula alata & $96.1(58-160)$ \\
Mean operative time (min) & $2(1-3)$ \\
Mean ASA score & $6.4(2-15)$ \\
Overall length of stay including & \\
thrombolysis (days) & $3.2(1-12)$ \\
Length of stay after TOD surgery & \\
$\quad$ days) & $34.4(6-58)$ \\
Mean follow-up time (months) &
\end{tabular}

ASA, American Society of Anesthesiologists.

This re-PTA resulted in relief of complaints in all 3 patients, resulting in a primary patency of $70 \%$ and primary assisted patency of $100 \%$ in this cohort. The mean time to reintervention was 32 days (range, 11-49).

The follow-up questionnaires were completed in $80 \%(8 / 10)$ of the patients and showed an improvement in function of the arm in all these patients at 38.9 months (range, 20-58). All (10/ 10) these patients were able to return to work and sport without limitations. Moreover, the mean TOS disability scale was 0.6 and the mean DASH score was 4.2 suggesting minor disabilities of the arm, shoulder, or hand. Quality of life measured with the adapted VEINES-SYM and VEINES-QOL resulted in a median VEINES-SYM score of 55.23 (IQR, 12.13) and VEINES-QOL score of 55.29 (IQR, 15.42). 


\section{DISCUSSION}

The proposed algorithm including thrombolysis, TA-TOD surgery, venolysis, and immediate PTA is effective with promising short and intermediate results. Using this treatment algorithm, both the anatomic substrate and the residual lesions can be effectively treated in the same admission. This ensures minimization of the risk of recurrent thrombosis and less in hospital days compared with other treatment algorithms. ${ }^{19-21}$ Follow-up by DASH score suggests equal functional outcomes compared with more invasive treatment algorithms. ${ }^{2,11-13,21}$ Moreover, the high return to work percentage and high quality of life score show minimal sequelae after adequate treatment in these patients with acute pUEDVT.

Our same admission treatment protocol is based on 3 principles: immediate thrombolysis within $24 \mathrm{hr}$ after presentation, transaxillary TOD with venolysis in the same admission, and intraoperative venography with immediate PTA to treat residual lesions. We try to accomplish thrombolysis within $24 \mathrm{hr}$ after presentation for all patients with acute pUEDVT because thrombolysis has the highest success rate if performed in patients with acute symptoms. ${ }^{4,20}$ Thrombolysis is followed by TOD surgery as soon as possible, because delayed surgery after thrombolysis can potentially lead to poorer functional outcomes and higher rates of recurrent

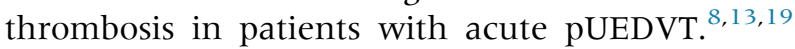
Although we advocate fast initiation of treatment by thrombolysis and TOD surgery, a mean of 7 days between the symptom onset and presentation in our clinic is present because of the delay of both patient and doctor. Because thrombolysis is proven useful within 14 days of onset, we believe this delay significant but acceptable. However, as fast initiation of adequate treatment is of importance, also delay of patient and doctor should be addressed to optimize treatment for patients with acute pUEDVT.

The preferred surgical approach differs between centers and is greatly dependent on the surgeon's preference and the method of treating residual stenosis. These intrinsic residual lesions of the ASV found after TOD surgery are relatively underexposed in the literature. The vein may remain stenotic because of fibrotic changes in the vein itself despite thrombolysis, surgical decompression, and venolysis. Besides, the ASV can lose the ability to dilate, which consequently causes sequelae especially during strenuous activities. Intrinsic residual lesions are commonly found after TOD surgery in patients with acute pUEDVT with percentages varying from 35\% to
$95 \% .^{10,11,20,22}$ These patients are presumed to be more at risk to develop a recurrent venous thromboembolism or chronic stenosis resulting in PTS. ${ }^{23}$ Evidence to subsequently guide treatment in these patients is limited and it remains unclear if the addition of PTA or vein patch placement after TOD surgery has a favourable effect on PTS rates and longterm functional outcome compared with TOD surgery alone. ${ }^{1,8}$ However, treatment algorithms with the best long-term outcome include a control venography and treatment of residual stenosis after TOD surgery. ${ }^{11,20,22,24}$ Moreover, the complication rates of these treatment modalities are not higher compared with TOD alone. ${ }^{11,19}$ Therefore, we also choose to assess the subclavian vein patency directly after TOD and subsequently treat residual stenosis in all patients.

Most treatment algorithms use intraoperative or postoperative venography to demonstrate patency or occlusion of the subclavian vein. ${ }^{10,11,19,24}$ We prefer an approach with intraoperative venography in a hybrid operating room. This allows for TOD surgery and endovascular treatment in the same procedure, resulting in same admission treatment for patients.

Although management of residual lesions is becoming of more importance, debate exists about the best approach. Different treatment algorithms with PTA, stents, vein patch placement, and/or venous bypass procedures have been published with varying results because restenosis can occur. ${ }^{1,12,21,25,26}$ Besides, the optimal timing for these procedures is debatable. ${ }^{27}$ Venous reconstruction procedures, in particular vein patch placements, are described in several cohorts with excellent patency rates. ${ }^{21,28}$ To adequately place a patch on the ASV, at least an infraclavicular approach should be performed. Some experts advise even a paraclavicular approach. ${ }^{29}$ These approaches combined with vein patch placement add time and complexity to the procedure. However, the results of this case series and other cohorts are comparable with vein patch placement and require a less invasive transaxillary approach combined with an endovascular intervention. ${ }^{11-13}$ We prefer the transaxillary approach allowing complete resection of the first rib from the costochondral junction to the articulation with the vertebral body's transverse process, leaving the neck of the first rib in situ, and access to the anterior scalene and subclavius muscles. $^{30}$ This offers excellent ability to remove all compressive elements in the thoracic inlet/outlet. Although complete first rib resection is not necessary for full venous decompression, both anterior and posterior residual rib stumps are associated with higher recurrence rates of neurogenic TOS 
and VTOS complaints and should therefore be avoided. ${ }^{28,31}$ In addition to the operative advantages, the transaxillary approach also has the best cosmetic effect. However, this approach does not allow reconstruction of the ASV by vein patch placement or jugular vein turndown procedures. The infraclavicular approach is also used as primary approach in algorithms with endovascular repair of residual lesions and has its own advantages. ${ }^{32}$ We do not primarily choose for this approach because it does not allow for complete first rib resection with thorough venolysis and has inferior cosmetic results.

We perform a PTA immediately after TOD surgery because this leads to faster functional recovery and less days of anticoagulant therapy compared with algorithms with delayed PTA. ${ }^{1,13}$ The long-term results defined by the recurrence rate of PTS must be awaited. Some clinicians use stents to treat (short segment) residual lesions. There is a lot of controversy on this issue. In some articles there is concern about long-term patency ${ }^{12,33-35}$ or limited options for later venous reconstruction, ${ }^{27,33,34}$ whereas another article claims excellent results. ${ }^{36}$ We reserve stent placement for persistent residual lesions in patients with severe sequelae despite several PTAs.

Surgical reexploration was required in 2 of 10 patients because of hematoma formation. Although no hemodynamic instability was reported, the question arises if recent thrombolysis puts patients at an increased risk for bleeding complications. On the basis of the pharmacokinetics of Alteplase, surgery can be performed safely after an interval of $4 \mathrm{hr}$. In our cohort, these 2 patients were operated on when we continued LMWH perioperatively and before the routine use of the Ligasure sealing device (Valleylab, Boulder, CO). Currently, we stop LMWH prophylaxis the evening before surgery. We did not have had any bleeding complications after these changes in our protocol. Nonetheless, the regular postoperative prescription of anticoagulants in combination with recent surgical trauma and endovascular treatment of fibrotic veins may pose the patients at an increased risk for bleeding complications.

\section{Limitations}

This case series has several limitations. First, the patency of the vein during follow-up is not checked in all patients with venography. However, routine venography during follow-up in the absence of symptoms is difficult to justify. Some use duplex ultrasonography to assess vein patency during followup but the results and sensitivity to assess significant stenosis in the ASV is limited. ${ }^{37}$ Therefore, we stopped with the routine use of duplex ultrasonography recently and only use venography as diagnostic imaging technique in patients with acute pUEDVT. We consider a daily activity questionnaire and the Dutch language version of the DASH score as best outcome measures during follow-up considering the limitations of duplex ultrasonography and venography. Second, we did not use the modified Villalta scale as outcome measure to assess severity of PTS complaints. The Villalta scale is originally developed for the assessment of lower-extremity PTS. ${ }^{38}$ It is suggested that a modified Villalta scale is superior to the DASH score in assessing outcome after acute pUEDVT. Unfortunately, the modified Villalta scale is not yet validated. Third, baseline questionnaire scores were not obtained before TOD surgery. Therefore, comparison of all used scores before and after surgery is not possible in this cohort. However, follow-up scores can be used to determine the level of functional disability and quality of life, and allow for comparison with other cohorts.

The "test-PTA" is used in addition to venography to assess vein patency after TOD surgery. However, this approach has not been validated to determine vein patency as whether it is combined with venography. Future studies should validate this diagnostic PTA and compare it to venography alone and/or intravascular ultrasound methods.

\section{CONCLUSIONS}

A same admission treatment algorithm for acute pUEDVT in patients with VTOS including thrombolysis, TA-TOD with extensive venolysis, and immediate venography with PTA is effective with promising short and intermediate results.

\section{CREDIT AUTHORSHIP CONTRIBUTION STATEMENT}

Niels Pesser: Methodology, Conceptualization, Funding acquisition, Formal analysis, Writing - original draft. Aron Bode: Methodology, Conceptualization, Writing - original draft. Jens Goeteyn: Writing - review \& editing. Joris Hendriks: Formal analysis, Writing - review $\delta$ editing. Bart F.L. van Nuenen: Writing - original draft. Marc R.H.M. van Sambeek: Writing - original draft. Joep A.W. Teijink: Methodology, Conceptualization, Writing - review \& editing.

\section{REFERENCES}

1. Illig KA, Doyle AJ. A comprehensive review of PagetSchroetter syndrome. J Vasc Surg 2010;51:1538-47. 
2. Thompson RW, Schneider PA, Nelken NA, et al. Circumferential venolysis and paraclavicular thoracic outlet decompression for "effort thrombosis" of the subclavian vein. J Vasc Surg 1992;16:723-32.

3. Lindblad B, Tengborn L, Bergqvist D. Deep vein thrombosis of the axillary-subclavian veins: epidemiologic data, effects of different types of treatment and late sequelae. Eur J Vasc Surg 1988;2:161-5.

4. Kearon C, Akl EA, Ornelas J, et al. Antithrombotic therapy for VTE Disease. Chest 2016;149:315-52.

5. Kahn SR, Comerota AJ, Cushman M, et al. The postthrombotic syndrome: evidence-based prevention, diagnosis, and treatment strategies: a scientific statement from the American Heart Association. Circulation 2014;130:1636-61.

6. van den Houten MML, van Grinsven R, Pouwels S, et al. Treatment of upper-extremity outflow thrombosis. Phlebology 2016;31 (1 Suppl):28-33.

7. Vemuri C, Salehi P, Benarroch-Gampel J, et al. Diagnosis and treatment of effort-induced thrombosis of the axillary subclavian vein due to venous thoracic outlet syndrome. J Vasc Surg Venous Lymphat Disord 2016;4:485-500.

8. Vazquez FJ, Paulin P, Poodts D, et al. Preferred management of primary deep arm vein thrombosis. Eur J Vasc Endovasc Surg Off J Eur Soc Vasc Surg 2017;53:744-51.

9. Lugo J, Tanious A, Armstrong P, et al. Acute Paget-Schroetter syndrome: does the first rib routinely need to be removed after thrombolysis? Ann Vasc Surg 2015;29:1073-7.

10. Chang KZ, Likes K, Demos J, et al. Routine venography following transaxillary first rib resection and scalenectomy (FRRS) for chronic subclavian vein thrombosis ensures excellent outcomes and vein patency. Vasc Endovascular Surg 2012;46:15-20.

11. Schneider DB, Dimuzio PJ, Martin ND, et al. Combination treatment of venous thoracic outlet syndrome: Open surgical decompression and intraoperative angioplasty. J Vasc Surg 2004;40:599-603.

12. Kreienberg PB, Chang BB, Darling RC, et al. Long-term results in patients treated with thrombolysis, thoracic inlet decompression, and subclavian vein stenting for PagetSchroetter syndrome. J Vasc Surg 2001;33(2 Suppl): S100-5.

13. Hawkins AT, Schaumeier MJ, Smith AD, et al. Concurrent venography during first rib resection and scalenectomy for venous thoracic outlet syndrome is safe and efficient. J Vasc Surg Venous Lymphat Disord 2015;3:290-4.

14. Illig KA, Donahue D, Duncan A, et al. Reporting standards of the Society for Vascular Surgery for thoracic outlet syndrome. J Vasc Surg 2016;64:e23-35.

15. Goeteyn J, van den Broek R, Bouwman A, et al. Interfascial plane Blocks reduce postoperative pain and Morphine Consumption in thoracic outlet decompression. Ann Vasc Surg 2020;66:301-8.

16. Aasheim T, Finsen V. The DASH and the QuickDASH instruments. Normative values in the general population in Norway. J Hand Surg Eur 2014;39:140-4.

17. Broholm R, Sillesen H, Damsgaard MT, et al. Postthrombotic syndrome and quality of life in patients with iliofemoral venous thrombosis treated with catheter-directed thrombolysis. J Vasc Surg 2011;54:18S-25S.

18. Bland JM, Dumville JC, Ashby RL, et al. Validation of the VEINES-QOL quality of life instrument in venous leg ulcers: repeatability and validity study embedded in a randomised clinical trial. BMC Cardiovasc Disord 2015;15. https://doi. org/10.1186/s12872-015-0080-7.
19. Taylor JM, Telford RJ, Kinsella DC, et al. Long-term clinical and functional outcome following treatment for PagetSchroetter syndrome. Br J Surg 2013;100:1459-64.

20. Doyle A, Wolford HY, Davies MG, et al. Management of effort thrombosis of the subclavian vein: today's treatment. Ann Vasc Surg 2007;21:723-9.

21. Molina JE, Hunter DW, Dietz CA. Paget-Schroetter syndrome treated with thrombolytics and immediate surgery. J Vasc Surg 2007;45:328-34.

22. Urschel HC, Razzuk MA. Paget-Schroetter syndrome: what is the best management? Ann Thorac Surg 2000;69: 1663-8. discussion 1668-1669.

23. Machleder HI. Thrombolytic therapy and surgery for primary axillosubclavian vein thrombosis: current approach. Semin Vasc Surg 1996;9:46-9.

24. de León RA, Chang DC, Hassoun HT, et al. Multiple treatment algorithms for successful outcomes in venous thoracic outlet syndrome. Surgery 2009; 145:500-7.

25. Feugier P, Aleksic I, Salari R, et al. Long-term results of venous revascularization for Paget-Schroetter syndrome in athletes. Ann Vasc Surg 2001;15:212-8.

26. Urschel HC, Patel AN. Surgery remains the most effective treatment for Paget-Schroetter syndrome: 50 years' experience. Ann Thorac Surg 2008;86:254-60. discussion 260.

27. Cai TY, Rajendran S, Saha P, et al. Paget-Schroetter syndrome: a contemporary review of the controversies in management. Phlebology 2020, 461-471;35.

28. Molina JE, Hunter DW, Dietz CA. Protocols for PagetSchroetter syndrome and late treatment of chronic subclavian vein obstruction. Ann Thorac Surg 2009;87:416-22.

29. Thompson RW. Comprehensive management of subclavian vein effort thrombosis. Semin Interv Radiol 2012;29:44-51.

30. Kashyap VS, Ahn SS, Machleder HI. Thoracic outlet neurovascular compression: approaches to anatomic decompression and their limitations. Semin Vasc Surg 1998;11: $116-22$.

31. Likes K, Dapash T, Rochlin DH, et al. Remaining or residual first ribs are the cause of recurrent thoracic outlet syndrome. Ann Vasc Surg 2014;28:939-45.

32. Bozzay J, Walker P, Ronaldi A, et al. Infraclavicular thoracic outlet decompression is superior to Supraclavicular thoracic outlet decompression for the management of venous thoracic outlet syndrome. J Vasc Surg 2018;68:e5-6.

33. Urschel HC, Patel AN. Paget-Schroetter syndrome therapy: failure of intravenous stents. Ann Thorac Surg 2003;75: 1693-6. discussion 1696.

34. Meier GH, Pollak JS, Rosenblatt M, et al. Initial experience with venous stents in exertional axillary-subclavian vein thrombosis. J Vasc Surg 1996;24:974-81. discussion 981-983.

35. Mallios A, Taubman K, Claiborne P, et al. Subclavian vein stent Fracture and venous Motion. Ann Vasc Surg 2015;29:1451.el-4.

36. Rajendran S, Cai TY, Loa J, et al. Early outcomes using dedicated venous stents in the upper limb of patients with venous thoracic outlet syndrome: a single centre experience. CVIR Endovasc 2019;2:22.

37. Brownie ER, Abuirqeba AA, Ohman JW, et al. False-negative upper extremity ultrasound in the initial evaluation of patients with suspected subclavian vein thrombosis due to thoracic outlet syndrome (Paget-Schroetter syndrome). J Vasc Surg Venous Lymphat Disord 2020;8:118-26.

38. Villalta S, Bagatella P, Piccioli A, et al. Assessment of validity and reproducibility of a clinical scale for the post-thrombotic syndrome. Haemostasis 1994;24(suppl 1):158a. 